\title{
In patients with cancer and venous thromboembolism (VTE), enoxaparin was as effective as warfarin for VTE prophylaxis and reduced fatal haemorrhage
}

\author{
Meyer G, Marjanovic Z, Valcke J, et al. Comparison of low-molecular-weight heparin and warfarin for the secondary \\ prevention of venous thromboembolism in patients with cancer: a randomized controlled study. Arch Intern Med \\ 2002;162:1729-35.

\section{QUESTION: In patients with cancer and venous thromboembolism (VTE), is a fixed dose of subcutaneous low molecular weight (LMW) heparin better than oral warfarin for secondary prophylaxis of VTE?}

\section{Design}

Randomised \{allocation concealed*\}†, blinded \{outcome assessors and data analysts $\mid+*$ controlled trial with primary follow up to 3 months.

\section{Setting}

25 centres in France.

\section{Patients}

146 patients $>18$ years of age (mean age 66 y, $55 \%$ women) with cancer of any type and deep venous thrombosis and/or pulmonary embolism. Exclusion criteria were previous heparin induced thrombocytopenia, allergy to iodine, pregnancy, fibrinolytic treatment within 3 days, oral anticoagulant use for $>5$ days, treatment with full dose heparin for this episode of VTE, major pulmonary embolism with shock, life expectancy $<3$ months, contraindication to anticoagulants, severe hepatic failure, planned major surgery or planned chemotherapy known to induce thrombocytopenia within 3 months. 138 patients $(95 \%)$ were included in the primary outcome analysis at 3 months.

\section{Intervention}

71 patients were allocated to a fixed dose of subcutaneous enoxaparin, $1.5 \mathrm{mg} / \mathrm{kg}$ body weight, once daily for 3 months. 75 patients were allocated to oral warfarin sodium, $6-10 \mathrm{mg}$, subsequently adjusted to achieve an international normalised ratio (INR) of 2.0-3.0 for 3 months.

\section{Main outcome measures}

Main outcome was treatment failure (symptomatic and objectively confirmed recurrent VTE and/or major bleeding at $3 \mathrm{mo}$ ). Secondary outcomes included major haemorrhage, fatal haemorrhage, mortality, and progression of underlying cancer.

\section{Main results}

The study was stopped prematurely because of slow patient accrual. Analysis was by intention to treat. At 3 months, patients in the enoxaparin and warfarin groups did not differ for treatment failure, major haemorrhage, mortality, or progression of underlying cancer (table). Patients in the enoxaparin group had a lower rate of fatal haemorrhage at 3 months (table). At 6 months, the groups did not differ for mortality or cancer progression.

\section{Conclusions}

In patients with cancer and venous thromboembolism, subcutaneous enoxaparin and oral warfarin were equally effective for secondary prophylaxis of venous Oncol 2000;18:3078-83. thromboembolism at 3 months. Patients who received enoxaparin had a lower rate of fatal haemorrhage than those who received warfarin.

$$
\begin{aligned}
& \text { *See glossary. } \\
& \text { †Information provided by author. }
\end{aligned}
$$

Enoxaparin $v$ warfarin for secondary prophylaxis of venous thromboembolism in patients with cancer and venous thromboembotism:

\begin{tabular}{lrrrl}
$\begin{array}{l}\text { Outcomes at } 3 \\
\text { months }\end{array}$ & Enoxaparin & Warfarin & RRR (95\% Cl) & NNT (Cl) \\
Treatment failure $\S$ & $10 \%$ & $21 \%$ & $51 \%(-10$ to 78$)$ & Not significant \\
\hline Major haemorrhage & $7 \%$ & $16 \%$ & $56 \%(-13$ to 83$)$ & Not significant \\
\hline Fatal haemorrhage & $0 \%$ & $8 \%$ & $100 \%(35$ to 100$)$ & 13 (7 to 38$)$ \\
\hline Mortality & $11 \%$ & $23 \%$ & $50 \%(-4.9$ to 77$)$ & Not significant \\
& & & RRI & NNH \\
Cancer progression & $17 \%$ & $13 \%$ & $27 \%(-40$ to 170$)$ & Not significant
\end{tabular}

$\ddagger$ Abbreviations defined in glossary; RRR, RRI, NNT, NNH, and $\mathrm{Cl}$ calculated from data in article.

$\S$ Treatment failure $=$ recurrent thromboembolism or major haemorrhage

\section{COMMENTARY}

Stable anticoagulant control is difficult to achieve in patients with cancer and VTE who are receiving warfarin because of hepatic dysfunction secondary to metastatic liver disease or effects of chemotherapy, interactions between warfarin and other cancer related drugs, and erratic absorption because of anorexia or gastrointestinal upset. ${ }^{1}$ This explains why such patients show a 6.0 fold increase in major bleeding and a 3.0 fold increase in recurrent VTE compared with patients without cancer. ${ }^{2}$ LMW heparin, while more costly than warfarin, is easy to administer, has predictable pharmacokinetics, and has been reported to be superior to warfarin as secondary prophylaxis in VTE.

Meyer et al showed that fixed dose LMW heparin resulted in fewer fatal haemorrhages at 3 months than warfarin, although all cause mortality and recurrent VTE or major bleeding did not differ. Study weaknesses include the small sample size and the low frequency of fatal bleeding ( $0 v 6$ patients) in the presence of 8 non-evaluable patients in whom bleeding, if it occurred in those receiving heparin, might have reversed the positive result seen here. Also, patient heterogeneity may have masked differential benefits of LMW heparin in particular subgroups.

Clinicians may, on the basis of this study, wish to use LMW heparin in patients with cancer and VTE who are considered to be at high risk of catastrophic bleeding if given warfarin. Larger studies, preferably stratified according to cancer type and stage, are required to define exact circumstances in which LMW heparin, as secondary prophylaxis, is superior to warfarin.

Ian Scott, MBBS, FRACP, MHA, Princess Alexandra Hospital Brisbane, Queensland, Australia

1 Kuijer PM, Hutten BA, Prins MH, et al. Prediction of the risk of bleeding during anticoaguant treatment for venous thromboembolism. Arch Intern Med 1999;159:457-60.

Hutten BA, Prins MH, Gent M, et al. Incidence of recurrent thromboembolic and bleeding complications among patients with venous thromboembolism in relation to both malignancy and achieved international normalized ratio: a retrospective analysis. J Clin

3 Levine MN, Lee AY. Treatment of venous thromboembolism in cancer patients. Semin Thromb Hemost 1999;25:245-9. 